\title{
A community based approach to bicycle helmet
}

\section{use counts}

\author{
Les R Becker, Marvin B Mandell, Kathleen Wood, Ellen R Schmidt, Frank O'Hara
}

\begin{abstract}
Objective-Bicycle helmet use has become an important measure of the effectiveness of bicycle safety programs and the effectiveness of helmet legislation. Accounts of analytical comparisons of observation site selection methods are scarce. This report addresses this gap by reporting the relative effectiveness and costs of two alternative approaches to the selection of observation sites for helmet use counts.
\end{abstract}

Methods-The community based (COBA) method of site selection entailed asking community informants to identify locations frequented by young bicycle riders. In the bicycle club/map (CLMA) method, site selections were based on recommendations from club members of sites at which cyclists were likely to be found and through examination of maps, keying on local features. These alternative site selection methods were compared in terms of their overall and cost effectiveness in locating youth riders.

Results-Despite fewer observer hours and fewer sites in a sparsely populated rural county, the COBA method yielded greater numbers of riding youth and from 1.9 to 4.6 times more youth riders per observer hour than did the CLMA method in two densely populated suburban counties. In addition, costs per youth rider observed associated with the COBA method were 2.9 to 7.0 times lower than those associated with the CLMA method.

Conclusions-Community based site identification is both more efficient in locating youth riders and more cost effective.

(Injury Prevention 1996; 2: 283-285)

Keywords: bicycle helmets, helmet observations, helmet observation sites, helmet use.

Bicycle safety initiatives involving helmet promotions, distributions, and subsequent helmet use counts are a current focus of program activities sponsored by the US National Center for Injury Prevention and Control. ${ }^{1}$ These initiatives are becoming a regular component of injury prevention and control programs across the US and other countries. Given the proven effectiveness of bicycle helmets in reducing head injury, ${ }^{2}$ helmet use has become an important measure of the effectiveness of bicycle safety programs ${ }^{3}$ and helmet legislation. ${ }^{45}$

Despite their increased application, detailed literature accounts of the various components of helmet count methodology are few, the contents of these accounts are inconsistent, and analytical comparisons of observation site selection methods are scarce. Several authors report that observations of bicycle helmet use were conducted, but these reports lack detailed descriptions of the observation methods, and especially lack descriptions of methods for the selection of sites at which observations were conducted. ${ }^{6-8}$ In one study, the authors report the selection of schools as sites where both an intervention had been implemented and associated helmet use observations had been conducted. ${ }^{9}$

Several other studies describe site selection methodology in varying degrees of detail, ${ }^{40-13}$ and one report asserts that the methods described were developed to maximize the number of children observed. ${ }^{14}$ However, none of the studies that report observation or site selection methodology investigates the possible effect of differing site selection methods on the numbers and ages of riders actually observed. Lastly, and notably, one literature account specifically reports that observations of riders under age 16 were halted because 'after hours of attempted observation, only a few bicyclists were seen because no areas had a significant concentration of bicyclists to be observed'. ${ }^{15}$

The major contributions of this paper are (1) to describe a new approach to site selection for helmet use counts of young riders and (2) to report the relative effectiveness of, and costs related to, two alternative approaches to the selection of observation sites for these counts. These approaches are referred to as the community based (COBA) and bicycle club/map (CLMA) approach, respectively.

\section{Methods}

\section{STUDY SITES}

These approaches were developed for use in evaluating the effects of legislation enacted in September 1991 and May 1992, respectively, in Montgomery and Allegany Counties, Maryland. The Montgomery county law requires persons less than 18 years of age, and the Allegany county law requires those less than 16 years of age, to wear helmets while riding on public thoroughfares. The evaluations were a joint activity of the Division of Injury and Disability Prevention and Rehabilitation of the Maryland Department of Health and Mental Hygiene (DHMH), in collaboration with the Montgomery and Allegany County Health Departments.

Montgomery County (1990 census population 757 027) bordering the District of Colum- 
bia's northwest region, is a densely populated ( $1531 \cdot 1$ persons/square mile) suburban county. The evaluation of the Montgomery County helmet use legislation was based on (1) helmet use counts conducted in Montgomery County four months before ('Montgomery I') and approximately nine months after ('Montgomery II') the passage of the legislation, and (2) helmet use counts at the same time in a control county, Baltimore County ('Baltimore I' and 'Baltimore II'). Baltimore County (1990 census population 692134 ) is also a densely populated ( 1156.6 persons/square mile) suburban county that did not have a county-wide helmet law.

Allegany County (1990 census population $74946)$ is a largely rural ( $176 \cdot 2$ persons/square mile) county with some light industry located in western Maryland. To evaluate the Allegany County helmet use legislation, prelegislation ('Allegany I') and postlegislation ('Allegany II') helmet use counts were obtained for the county. No suitable control county was available for this evaluation study.

\section{OBSERVATION METHODS}

Common observation, data handling, and analysis methods were employed in the Montgomery II Baltimore II, Allegany I, and Allegany II helmet use counts. Observers received standardized training before their participation in field observations. For inexperienced observers, training typically occurred 1-2 days before the first observation session. A standardized training lesson described the procedure for identifying and numbering passing bicyclists and independently assessing age group, gender, race, and helmet use, and recording this information on a standardized form. Several teams of two paid observers drove in automobiles along predetermined routes in all three counties. Observations were conducted from the vehicle or from a nearby vantage point between the hours of 9:00 am and 4:00 pm during the summer months. These methods have been described in detail by Cote et $a l^{4}$ and have been shown to result in high degrees of interobserver agreement for gender, race, and helmet use. After collection, data were entered on a personal computer and an algorithm applied to clarify discordant observations of age. Subsequently, a series of tables was generated.

Cost data were developed from the payroll of observers and DHMH staff, and other records associated with the observation activities. Because the Montgomery I and Baltimore I

Table 1 Numbers and rates of adult and youth bicyclists observed, by site selection method and county

\begin{tabular}{lllllll}
\hline $\begin{array}{l}\text { Site } \\
\text { selection } \\
\text { method }\end{array}$ & County & $\begin{array}{l}\text { Riders } \\
<19 \text { years }\end{array}$ & $\begin{array}{l}\text { Riders } \\
19+\text { years }\end{array}$ & $\begin{array}{l}\text { Total } \\
\text { hours }\end{array}$ & $\begin{array}{l}\text { Total riders/ } \\
\text { observer hour }\end{array}$ & $\begin{array}{l}<16 \text { riders/ } \\
\text { observer hour }\end{array}$ \\
\hline CMLA & Montgomery II & 36 & 178 & 30 & $7 \cdot 1$ & $1 \cdot 2$ \\
CMLA & Baltimore II & 63 & 162 & 30 & $7 \cdot 5$ & $2 \cdot 1$ \\
COBA & Allegany I & 99 & 31 & 18 & $7 \cdot 2$ & $5 \cdot 5$ \\
COBA & Allegany II & 73 & 48 & 18 & $6 \cdot 7$ & $4 \cdot 1$ \\
\hline
\end{tabular}

helmet use counts used different observation methods, they are not considered in our comparison of the two methods for site selection.

\section{SITE SELECTION METHODS}

Whereas a common observation method was employed in the Montgomery II, Baltimore II, Allegany I, and Allegany II helmet counts, the approach to site selection used in Montgomery II and Baltimore II differed from the approach to site selection in Allegany I and Allegany II. In particular, observation sites for Montgomery II and Baltimore II were selected using the CMLA method. In this method, observation sites were selected based on recommendations from bicycle club members of sites at which cyclists were likely to be found. They were also located through examination of maps, keying local features, such as parks, bike trails, community pools, and residential streets. Sites were field checked for safety and suitability before their inclusion in the study. The Montgomery II and Baltimore II observations were conducted over 30 observation hours per county over a four week period. The observation hours in each county were distributed among 40 sites in the respective county.

In contrast to the site selection approach used in Montgomery II and Baltimore II helmet counts, observation sites used in the Allegany I and Allegany II helmet counts were selected using the COBA method. This entailed asking community knowledgeable informants to identify locations in their neighborhoods frequented by non-adult bicycle riders. These sites were also field checked for safety and suitability before this inclusion in the study. The prelegislation and postlegislation observation activities in Allegany County were conducted on each of two Saturdays, one year apart. Each observation activity consisted of a one day 'snapshot' of bicycle helmet use conducted over 18 total observation hours distributed among 24 sites.

\section{Results}

The results of the observation activities are shown in table 1. In Allegany I and Allegany II, where the COBA site selection method was employed, despite fewer observer hours and fewer sites, greater numbers of riding youth were observed than in either Montgomery or Baltimore Counties. This COBA site selection method yielded from 1.9 to 4.6 times more under 16 riders per observer hour in the sparsely populated rural county than did the CLMA approach in the more densely populated suburban counties. Remarkably, over the course of all observations in all counties, only one team reported a brief $(<30$ minute) episode of light rain.

The costs of the observations are shown in table 2. Costs per under 16 rider associated with the CLMA approach were $2 \cdot 9$ to $7 \cdot 0$ times greater than those associated with the COBA method of site selection. Thus, COBA site identification is both more efficient in locating young riders and more cost effective. 
Table 2 Observation costs of adult and youth bicyclists, by site selection method and county

\begin{tabular}{|c|c|c|c|c|c|c|c|}
\hline \multirow{2}{*}{$\begin{array}{l}\text { Site } \\
\text { selection } \\
\text { method }\end{array}$} & \multirow[b]{2}{*}{ County } & \multirow[b]{2}{*}{$\begin{array}{l}\text { Riders } \\
<19 \text { years }\end{array}$} & \multirow[b]{2}{*}{$\begin{array}{l}\text { Riders } \\
19+\text { years }\end{array}$} & \multirow[b]{2}{*}{$\begin{array}{l}\text { Cost } \\
\text { (S) }\end{array}$} & \multicolumn{3}{|c|}{ Cost/rider (S) } \\
\hline & & & & & $\begin{array}{l}\overline{A l l} \\
\text { ages }\end{array}$ & $\begin{array}{l}>16 \\
\text { years }\end{array}$ & $\begin{array}{l}<16 \\
\text { years }\end{array}$ \\
\hline CMLA & Montgomery II & 36 & 178 & 2035.00 & 9.51 & 11.43 & 56.53 \\
\hline CMLA & Baltimore II & 63 & 162 & 2035.00 & 9.04 & 12.56 & 32.30 \\
\hline COBA & Allegany I & 99 & 31 & 800.00 & 6.15 & 25.81 & 8.08 \\
\hline COBA & Allegany II & 73 & 48 & 800.00 & 6.61 & 16.67 & 10.96 \\
\hline
\end{tabular}

\section{Discussion}

Our work demonstrates that (1) careful consideration of site selection methods is important because of its influence on observation activities, (2) community input enhances the ability of public health professionals and community coalition members to identify areas frequented by youth riders and therefore more effectively study the habits of youth riders, and (3) the use of paid observers for helmet use counts is feasible and effective.

This study demonstrates that the COBA approach identifies sites that yield relatively large numbers of young riders. However, we have not examined whether the resultant sample is representative and unbiased relative to the intended target population. Clearly, the representativeness of the sample will be increased by ensuring that the panel of community informants from which site information is obtained spans a representative cross section of the community of interest. Moreover, a logical step for future research is to compare the COBA approach with other site selection approaches that have been described in the literature. ${ }^{40-14}$

The promotion of bicycle safety and helmet use is occurring in a number of different formats across the country, including those based in state or local governments, community coalitions, and various other forms of publicprivate partnerships. The evaluation methods described here are readily adaptable to all these situations. In Maryland, the observations have been conducted by high school and college students. 'Training' for the observation activities can be accomplished in less than 30 minutes and the trainer need not be a public health professional; all that is required of the trainer is an understanding of the goals of the observation activity and a thorough under- standing of the methods. The data form itself is straightforward, and at a minimum, the resulting data can be summarized by any individual familiar with a basic spreadsheet. Further development of these methods is planned as we expand the scope of our evaluation activities.

This work was supported in part by grant number $\mathrm{H} 28$ CCH301618 from the US Centers for Disease Control and Prevention and grant number MCJ-243A07 from the US Bureau of Maternal and Child Health. The authors thank Dr Rick Waxweiler for encouraging this line of research. We are grateful to Dr Barry Pless and an anonymous reviewer for their thoughtful comments on an earlier draft of this manuscript. We thank Ms Selina Haq for her invaluable assistance in editorial matters and in the preparation of this manuscript.

1 Centers for Disease Control and Prevention. Injury control recommendations: bicycle helmets. Morbidity and Mortality Weekly Report Vol 44, number RR-1. Atlanta: tality Weekly Report Vol 44, number RR-1. Atlanta:
Epidemiology Program Office, Centers for Disease ConEpidemiology Program Office,

2 Thompson RS, Rivara FP, Thompson DC. A case-control study of the effectiveness of bicycle safety helmets. $N$ Engl f Med 1989; 320: $1361-7$

3 Dannenberg AL, Gielen AC, Beilenson PL, Wilson $\mathrm{MH}$, Joffe A. Bicycle helmet laws and educational campaigns: an evaluation of strategies to increase helmet use. $A m \mathfrak{f}$ Public Health 1993; 83: 667-74.

4 Cote T, Sacks JJ, Lambert-Huber DA, et al. Bicycle helmet use among Maryland children. Pediatrics 1992; 89: 1216-20.

5 Cameron MH, Vulcan AP, Finch CF, Newstead SV. Mandatory bicycle helmet use following a decade of helmet promotion in Victoria, Australia: an evaluation. Accid Anal Prev 1994; 26: 325-37.

6 Winn GL, Jones DF, Bonk CJ. Taking it to the streets: helmet use and bicycle safety as components of inner-city youth development. Clin Pediatr (Phila) 1992; 31: youth $672-7$.

7 Weiss BD. Trends in bicycle helmet use by children: 1985 to 1990. Pediatrics 1992; 89: 78-80.

8 Marshall J, White M. Evaluation of the compulsory helmet wearing legislation for bicyclists in South Australia. Office of Road Safety Report Series 8/94. Walkerville, South Australia: Office of Road Safety, South Australian Department of Transport, 1994.

9 Morris BAP, Trimble NE. Promotion of bicycle helmet use among schoolchildren: A randomized clinical trial. Can $\mathcal{F}$ Public Health 1991; 82: 92-4.

10 Drummond AE, Ozanne-Smith EJ. The behaviour and crash involvement risk of child pedestrians and bicyclists: a traffic exposure study. Report No 17. Victoria, Australia: Monash University Accident Research Centre, 1991.

11 Parkin P, Morris B, Chapman M, et al. Measurement of bicycle helmet use by direct observation: accuracy of a measurement methodology. Pediatr Perinat Epidemiol measurement methodolo

12 Parkin P, Spence LJ, Hu X, et al. Evaluation of a promotional strategy to increase bicycle helmet use by children. Pediatrics 1993; 91: 772-7.

13 Rowe BH, Thorsteinson K, Bota GW. Bicycle helmet use and compliance: a northeastern Ontario roadside survey. Can $\mathcal{F}$ Public Health 1995; 86: 57-60.

14 DiGuisseppi CG, Rivara FP, Koepsall TD, Polissar L. Bicycle helmet use by children: evaluation of a community-wide helmet campaign. $\mathcal{F} A M A$ 1989; 262: 2256-61.

15 Macknin ML, Medendorp SV. Association between helmet legislation, bicycle safety education and use of bicycle helmets in children. Arch Pediatr Adolesc Med 1994; 148: 225-59.

Successful child restraint program

An issue of Status Report describes the not unexpected but nevertheless satisfying effect of a pilot program in Durham, NC that increased proper child restraint use through a combination of enforcement and education (Click It or Ticket). At pilot schools rates went from 36 to $64 \%$ in one case, and from 49 to $71 \%$ in another (Status Report, Insurance Institute for Highway Safety, 31, 5, 1996).

\section{Animal crackers}

The indomitable, eagle eyed, Jan Shield, noting my interest in moose injuries, sent me a series of other papers describing animal related injuries. They include roosters (ocular), magpies (ocular), crocodile (transection of the torso or decapitation), and quokka bites (a small wallaby) (JS). 